\title{
T. B. de Sousa Carvalho ${ }^{(*)}$
}

Lino de Morais Leme

O motivo que hoje nos congrega é o de prestar homenagem ao mestre a amigo, professor Teófilo Benedito de Sousa Carvalho, no trigésimo dia de seu passamento, ocorrido a 19 de setembro último.

Nasceu nesta Capital a $1^{\circ}$ de dezembro de 1869, sendo filho de d. Maria Isabel Schmidt de Sousa Carvalho e do dr. Francisco Aurélio de Sousa Carvalho, que foi diretor da Instrução Pública do Estado e deixou fama como professor de matemática do antigo Curso Anexo desta Faculdade.

Pôs-lhe o pai o prenome Teófilo Benedito, chamando-o, assim, "servo abençoado de Deus", como a pôr o filho sob as bênçãos do Céu. Ao prenome seguia-se o nome de famijlia - Sousa Carvalho, como a indicar que êle seria modesto como o seixo (do qual Sousa), que não aparece nas massas dágua ou jaz olvidado na praia, e firme como o carvalho, do qual disse La Fontaine que a copa "brave l'effort de la tempête."

Bacharelou-se em 19 de dezembro de 1892 (o curso era então de quatro anos), aos 23 anos de idade, tendo sido discípulo de Pedro Lessa, Frederico Abranches, Dino Bueno, Brasílio dos Santos, Leite de Morais, Amâncio de Carvalho, Aureliano Coutinho, João Monteiro e João Mendes Júnior.

(*) Oraçâo proferida a 19 de setembro de 1945, trigésimo dia de seu passamento. 
Fez parte de uma turma de aproximadamente cem alunos, da qual se destacam, entre outros, Fernando Luís Vieira Ferreira, desembargador, autor de valiosos trabalhos jurídicos, Lisipo Antônio do Amaral Garcia - que devia brindar a literatura jurídica com dois livros sôbre registros públicos, a exemplo de Coviello, no direito italiano -, Washington Luís Pereira de Sousa, ex-presidente da República, Paulo Teixeira, João Cesar Bueno Bierrenbach, o tribuno campineiro. Foram seus contemporâneos Luiz 'Torres de Oliveira, José Maria Lisboa Júnior, Alcântara Machado, Paulo de Lacerda, José Severiano de Rezende, José Mariano Corrêa de Camargo Aranha, Artur Cesar da Silva Whitaker, Júlio Cesar de Faria; e foi comtemporâneo de Astolfo Rezende, Silvio de Almeida, Pedro Moacir, Gabriel de Rezende, Cândido Mota, Sá Freire, Reinaldo Porchat, Eduardo de Campos Maia, Estevão Pinto, Francisco de Paula e Silva, Mário Bulcão, José Mendes, Antonino Vieira. Otáviano Vieira, Venceslau Braz, Joaquim Celidônio, Macedo Couto!

Durante seu curso houve dois acontecimentos: a proclamação da República e a nomeação de lentes, sem concurso, pelo ministro Benjamim Constant. Este fato teve repercussão no seio da mocidade acadêmica e da Congregação, que, empossando os lentes nomeados, declarou-os dignos da investidura para a qual seriam indicados, se fôra ouvida, mas reivindicou o seu direito de escolher os professores, por meio de concurso, como uma de suas mais importantes atribuições.

Cinco anos depois de formado, isto é, aos 28 de idade, já o advogado Sousa Carvalho se inscrevia em concurso, juntamente com Dario Ribeiro, José Bonifácio de Oliveira Coutinho e Pânfilo de Assunção, para substituto da 2. ${ }^{a}$ secção, apresentando a tese. - "O orçamento do Brasil - seu preparo e decretação".

A êsse tempo o candidato devia apresentar proposições sôbre as Cadeiras da Secção e uma dissertação. As pri- 
meiras versaram sôbre Economia Política, Ciência das Finanças e Contabilidade do Estado, Ciência da Administração e Direito Administrativo.

As proposições apresentadas por nosso homenageado revelam a firmeza de seus conhecimentos. Dentre elas destaco as seguintes: em Economia: "Nos Países onde superabunda o papel moeda incovertível, a moeda metálica deixa de ser instrumento direto de permuta, ficando, para todos os efeitos econômicos, equiparada à mercadoria"; "O bimetalismo não satisfaz as exigências de um bom sistema monetário". Em Finanças: "O imposto único éi uma utopia irrealizável"; "O imposto de capitação ofende a base cardeal do sistema monetário. Êle é desigual e, por isso mesmo, anti-democrático".

A primeira é uma consequência da aplicação da lei de Gresham - a existência do papel moeda expele a moedi metálica. A questão do monometalismo e do bimetalismo não era simples: basta recordar que Almeida Nogueira, em sua Economia Política, considera insuperável a dificuldade em resumir os argumentos de uma e de outra corrente, e que adotam o bimetalismo a Itália, Bélgica, Suiça, Grécia, Espanha e Estados Unidos. Também Almeida Nogueira é categórico: “ dois padrões diversos — são cousa absurda em ciência. É a ausência de padrão".

O imposto único (tese de Finanças), é o preconizado pela escola fisiocrática, com êste fundamento: "Só a terra produz um rendimento líquido, portanto é sôbre ela, sómente, que recaem todos os impostos, e, para que seja menos onerada, deverá haver um imposto único", contra o qual assim se manifesta René Stovrm: "A unidade do imposto reuniria em si todos os defeitos e injustiças dos demais impostos; é inconciliável com o progresso da civilização, com a sociedade moderna, onde a riqueza se reveste de mil formas diversas, incessantemente variáveis, e às quais o imposto deve adaptar-se" (Systèmes généraux d'impôts). 
O imposto de capitação (outra tese), que gravava diretamente a pessôa, foi abolido pela lei n. 2.670, de 20-10-1875. Não estava, porém, fora de cogitação, tanto que houve tentativas para restabelecê-lo, ambas malogradas: a de Menezes Prado, em 1896, e a de Eloi Chaves, em 1904, a-pesar-da: aplicação que êste lhe pretendia dar — a reorganização de nossa marinha de guerra.

Na dissertação, o nosso homenageado critica o processo de elaboração de nossa lei de meios e se manifesta contrário à idéia de se considerar, no orçamento, uma parte fixa e outra variável: "O remédio, diz êle, está antes no cumprimento do dever patriótico de cada um do que na severidade e restrições do direito escrito - Quid vanae leges sine moribus?"

Outras vêzes volta êle â liça: em 1902, para a 7.a seç̧ão: (Direito Comercial), com Alfredo Valadão, Paulo de Lacerda, José Mendes e Frederico Steidel, que fol o escolhido; em 1906, para a $10^{a}$ secção (Filosofia de Direito e Direito. Romano); em 1908; com Estevão de Almeida, que foi o indicado, para a 5. ${ }^{\text {a }}$ secção (Direito Civil e Legislação Com-parada do Direito Privadio); em 1911, para professor extra-. ordinário, efetivo; em 1914, para a $1 .^{a}$, a $3 .^{a}$ e a $7 .^{a}$ secções. Para a $3{ }^{a}$, com Dionísio da Gama, José Augusto Cesar e Spencer Vampré; para a $7 .^{\mathrm{a}}$, com Aureliano de Gusmão. Foi então indicado para a $\mathbb{1}^{\mathrm{a}}$ secção, e, nomeado a 20 de outubro de 1914, toma posse no dia 28 dêsse mês.

I Finalmente, a 29 de maio de 1918, é nomeado catedrático, na vaga deixada pelo professor José Mendes, assassinado em Mocóca.

Durante êsse interregno, do primeiro concurso à nomeação para catedrático, não esteve o professor Sousa Carvalho afastado do ensino, pois exerceu as funções de lente catedrático de Direito Civil, na extinta Universidade de S. Paulo, e de Direito Comercial e de Direito Internacional, Diplomacia, História dos Tratados e Correspondência Diplo-mática, da Escola de Comércio "Álvares Penteado". 
Os concursos referidos versaram sôbre a maıorıa das Cadeiras desta Faculdade: o de 1902 foi para a secção de Direito Comercial; o de 1906, para a de Filosofia do Direito e Direito Romano; o de 1908, para a de Direito Civil, o de 1914, para tres secções.

Para êsses concursos, apresentou o nosso saudoso conpanheiro teses valiosas, que foram recompensadas com as classificações que obteve; depois com a nomeação para professor extraordinário, efetivo, e, afinal, para professor catedrático.

Folhando essas teses, ficamos admirados da facilidade com que o nosso homenageado versava questões sôbre os mais variados ramos de direito, sustentando sempre a melhor doutrina.

Na tese sôbre Enciclopédia jurídica, parte êle da enciclopédia de Marciano Capela, que publicou a sua obra no sec. $5 .^{\circ}$, reunindo as ciências em que se resumia o saber jurídico da época - gramática, dialética, retórica, geometria, astrologia aritmética e música, e, após referir-se a enciclopédias gerais, entre as quais a Encyclopédie ou dictionnaire raisonné des sciences, des arts et des métiers, em 35 volumes, planejada por Diderot, e que contou com a colaboração de gandes vultos da época, entra no exame do objeto da nova Cadeira, que não é um estudo aprofundado de todo o direito, mas introdução geral ao estudo do direito (nome que lhe foi dado depois). Em seguida, recorda as palavras de Eschbach, notável professor da Universidade de Strasburgo: "Il faut commencer l'étude du Droit par l'Encyclopédie, comme on commence celle de la géographie par la mappemonde". E recorda que VircroR Cousin, em 1840, na pasta da Instrução Pública, no Gabinete Thiers, propunha a criação dessa Cadeira, dizendo vir propôr o preenchimento de uma lacuna que foi deixada no ensino do Direito.

Para outros concursos, escreveu Sousa Carvalho as teses: Erro de direito na conditio indebiti; $A$ novacão no Direito 
Romano e no Direito Civil; Primeira atribuição conferida ao Congresso Nacional Brasileiro. O Parlamento satisfaz o préceito constitucional.

$\mathrm{Na}$ primeira, põe em relevo a diferença entre o Direito Romano e o Direito Civil moderno, quanto ao conceito de erro de direito na conditio indebiti. Quanto àquele, acompanha Savigny, Cujacio, Donellus, Merlin contra Vinnius e Mëhlenbruck; isto é, fundado na lei $10 \mathrm{C}$ (1-18) "Cum quis jus ignorans, indebitam pecuniam solverit, cessat repetitio", sustenta que, salvo as exceções expressas, o Direito Romano não admite a repetição por erro de direito. Nesse trabalho refere-se a Fubini e Laurent, que admitem a repetição do indébito por êrro de direito, em todos os casos, no direito moderno.

Em A Novação, faz um estudo sistemático dêsse institudo jurídico.Tratando do animus novandi, mostra a diferença entre o Direito Romano, que exige manifestação expressa, e o direito moderno, que abrandou o rigor, admitindo o animus, mesmo quando não explícito. Sustenta ser essa a interpretação do art. 1273 do Cod. francês — "La novation ne se présume point; il faut que la volonté de l'opérer résulte clairement de l'acte"

Quanto à novação necessária ou judiciária, existente no D. R. antes de Justiniano, derivando os seus efeitos da litis contestatio ou do judicium, recorda que SAVIGNy a admiiiu no vol. 5, p. 33, de seu Système, mas retificou a sua opinião, no v. 6 , p. 27 e 28; e, lembrando que ainda MARCADÉ e Aubry et Rau são dela partidários, enfileira-se ao lado de Lacerda de Almeida, Paula Batista e João Monteiro, que contestam haver essa espécie de novação.

Examinando novamente a questão orçamentária, na terceira tese, critíca energicamente o sistema de orçamento extraordinário e, depoís de mostrar que sòmente a catástrofe de Sédan mostrou a Napoleão III que se não pode violar impunemente as leis econômicas, escreve: "A lição, infelizmente, não nos tem aproveitado. O Brasil é um dos 
países onde o poder executivo mais tem usado e abusado da faculdade de decretar créditos além das previsões do. orçamento. Embalde as leis de 9 de setembro de 1850 e 20 de outubro de 1977 estabeleceram regras limitando a confecção do orçamento extraordinário. A irresponsabilidade do poder entre nós e o hábito de não se contar com o texto legal, tem feito daquele dispositivo letra morta. A ditadura financeira há sido, por assim dizer, a norma comum. De enxurriada, em 1895, o Poder Legislativo aprovou créditos extraordinários suplementares na enorme cifra de cento e vinte e sete mil contos". A seguir criticando a sugestão de Dídimo, presidente do Tribunal de Contas, no sentido de se ampliar ao máximo a importância dos créditos suplementares do exercício, diz: "Quem não prevê a série extensa de perigos daí resultantes? Para nós, o arbítrio é sempre o arbítrio, e como tal abominável. Á sua metodização preferimos a extirpação. O Parlamento se reune anualmente. É seu dever, também anualmente, decretar a lei de meios. Seja essa a tarefa primeira que o preocupe; ela é que mais diretamente afeta os interesses do contribuinte." Depois fala do deficit, que atribui ao "espirito de partido, entre nós tão exigente, a benevolências, falsas conveniências de ocasião, outras variadas razões de decidir."

Que não diria o nosso pranteado mestre, diante da situação atual, quando a máquina para fabricar dinheiro trabalha incessantemente? Apontam, para a inflação, duas razões: a guerra e a necessidade de emitir para pagar as exportações. Ora nada mais fácil do que refutar tais assertos...

Para ser a guerra, seria mister que as nossas despesas, com a mesma, tivessem calado fundamente. Ora: mandámos para os campos de batalha uma pequena fôrça expedicionária, que, no entanto, se cobriu de glórias, que nós exaltámos e que a história não esquecerả.

Se o deficit se devesse ao pagamento das exportações, significaria isso que o Govêrno as comprou, pagando em 
papel moeda, para receber posteriormente as "divisas" ou as cambiais ouro. Ora: recebendo estas e vendendo-as aos importadores, o Govêrno receberia o que emitiu, e desapareceriam os efeitos da inflação.

Portanto, nem uma nem outra servem para justificar as incessantes e colossais emissões, que estabeleceram, no pais, a carestiai de vida; e novas emissões continuam a agravar indefinidamente. $\mathrm{E}$ deficit derivado.

Não vamos referir os numerosos trabalhos forenses, os discursos e os pareceres publicados pelo professor Sousa Carvalho, e que atestam ter o seu escritório assinalado movimento. Mas não nos furtamos ao prazer da referência a um trabalho seu, sôbre nacionalidade e naturalização, na Rev. da Fac., v. 29 (ano de 1933), em que sustenta, com Stoicesco, a naturalização que, uma vez concedida definitivamente, adquire efeitos absolutos e irrevogáveis, tornando-se um direito adquirido, na expressão do Foignet. E conclui que, no direito pátrio, sòmente podia ela ser revogada nos casos estabelecidos na Constituição Federal e no decreto n. 6.948, de 1908.

Queremos citar também um outro trabalho sôbre a matéria de sua Cadeira, no qual fala na fraude de os cônjuges de Estado onde não há o divórcio procurarem país em que o mesmo existe, para obtê-lo, como se dá em nossos dias. E advoga a aplicação da lei de logar em que foi deJebradio o casamento, para coibir a fraude.

Em alguns de seus trabalhos, refere-se Sousa Carvalho à tenacidade que punha na conquista do logar de professor. Na tese sôbre Enciclopédia jurídica, escreve: "Se tanto não alcançarmos, sirva ela ao menos aos principiantes como simples exemplo de um nobre e persistente esforço que lhes deixa um operário do Bem, do Honesto e do Justo, em busca de uma elevação intelectual". Em A Novação, na dedicatória, escreve:" Aos meus filhos - o trabalho honesto nobilita o homem, a tenacidade nele, quando não alcança o fim colimado, enriquece sempre com alguma cousa impre- 
vista”. Na sôbre Erro de direito, diz “. . se non licet omnes adire Corinthum, êstes esforços atestarão, ao menos, uma tenacidade nobre e elevada". E no prefácio da Miscelânea: “ Bendizemos a tenacidade de um esfôrço e da resignação que nos encorajam ao prosseguimento neste tentamen; élo benéfico que nos prende e que com alguma cousa sempre nos recompensa - o cultivo de nosso espírito", palavras de fé e ao mesmo tempo de conformidade, e não um brado de revolta.

É que o professor Sousa Carvalho era um bom, dominado pela fé e pelo sentimento de justiça.

A sua bondade erá proverbial. Por isso e por seu apêgo à tradição, segundo a qual não haveria reprovações no quinto ano - já há vários anos desapareceu essa injustificável tradição, substituida por uma tolerância larga, porém não cega -, em um exame, vendo um examinando aflito na prova escrita, teria dito ao vizinho do mesmo "que o ajudasse."

Eu fui parte em um caso que confirma essa bondade, aliada ao espúrito de justiça. Éramos, êle e eu, membros da Comissão Central de Sindicância, juntamente com os drs. Luiz Torres de Oliveira e João Cesar Sobrinho, da magistratura, e Luiz de Sampaio Freire, da classe dos advogados. Foi-me distribuido um processo, resultado de uma queixa apresentada à Junta de Sanções pelo nosso saudoso mestre, por parte de um seu constituinte. Não conheceu êle a marcha do processo, porque na primeira sessão dessa Comissão, para pôr cobro à publicidade que prejudicava muitos inocentes, propús, e foi aprovado, que dos processos sómente tivessem vista os indiciados ou seus advogados. O meu parecer, nessa sindicância, foi favorável ao acusado, em face da prova produzida. Para mostrar que êsses pareceres eram fundados em larga documentação, de se lembrar que processos havia com vários volumes (fui relator de um que tinha oito volumes). Tendo conhecimento da resolução tomada em sua ausência, dado o seu impedimen- 
to, ficou êle bastante zangado, segundo me informaram; mas, depois, examinando os autos, viu que outro não podia ser o parecer. Incomodado com a expansão que tivera, e da qual supunha eu teria conhecimento, no dia seguinte, quando regressei do interior, fui alvo, por parte dele, de especiais demonstrações de amizade. A bondade e o espírito de justiça haviam superado a crise, como o demonstraram palavras que lhe ouvi, depois: quando, ao tempo das derrubadas de interventores, que pouco tempo ficaram no poder, vendo certa ocasião o seu nome apontado entre os indicados para a Interventoria, dissera-me que eu seria o seu secretário da Justiça.

Grão Mestre da Maçonaria, dela se despediu quando se converteu ao catolicismo, em 1908. Foi um dos fundadores da Adoração Noturna em S. Paulo, e do Apostolo da Oração da Catedral da Sé, onde exerceu o cargo de presidente. Era também irmão do Santíssimo Sacramento e da Ordem Terceira de Nossa Senhora do Carmo, com cujo hábito foi sepultado, como desejou.

Vem daí a sua amizade com os irmãos Maximino da Silva Leite, a quem dedica um dos seus trabalhos, e d. Joaquim Mamede da Silva Leite, que o levou como um dos padrinhos, ao ser sagrado bispo auxiliar de Campinas. Contava êle jocosamente que, após a sagração, o novo bispo percorria a Catedral, de acôrdo com o ritual, acompanhado por seus paraninfos e sacerdotes, abençoando os fieis; e que, nesse ato, o outro padrinho acenava discretamente aos fieis para que se ajoelhassem, dizendo à meia voz e apontando para o nosso homenageado, revestido das insígnias doutorais: - "Bispo sírio!"

Nomeado catedrático em 1918, foi a minha turma, a de 1919, a primeira a receber desde o comêco do ano as lições do novel catedrático. Além dos dessa turma - professores Mário Masagão, Ernesto Leme, Honório Monteiro, Noé Azevedo, Soares de Melo, Siqueira Ferreira e quem vos fala, foram alunos seus os professores Braz de Sousa 
Arruda, Cesarino Junior, Mendes de Almeida, Basileu Garcia, Ataliba Nogueira, Miguel Reale e Monteiro de Barros, isto é, 14 professores catedráticos, além da maioria dos livres docentes.

Como professor, Sousa Carvalho fez parte de Comissões Examinadoras, em exames de admissão e em concursos. Nestes dirigia-se aos candidatos pedindo esclarecimentos para espancar as dúvidias que a tese suscitava a seu espírito; e, sem descer a minúcias, apresentava objeções de carater geral, que às vezes deixavam o candidato em dificuldades para sair da teia urdida.

Era conhecido como "O Pagé", não porque o seu aspéto imponente lhe desse o ar de um piaga, como seria de supôr, mas porque o pai, com carinhosa brejeirice, lhe dera aquela alcunha, quando o filho em tenra idade, por achá-lo com o aspecto de índio. Concorreu para isso, certamente, o prenome comprido do filho, a reclamar uma forma curta de designação. Se em tenra idade tinha êle o aspéto que lhe achou seu bom genitor, perdeu-o com o correr dos anos, para adquirir o ar professoral oriundo da vocação que seguiu.

A alcunha se converteu em o nome do primeiro filho do homenageado. Além dêsse, deixou êle mais nove filhos - os drs. Arí José, Clélio, Ernani e Maximiano, e as exmas. Filhas - Isabel, Maria, Odette, Iolanda e Maria da Conceição, que são os remanescentes da numerosa prole havida de seu único consórcio com a exma. Sra. D. Orfila Galvão de Sousa Carvalho, falecida em 1934, ano das bôdas de ouro do casal, constituido em 1894.

Aposentado, por haver atingido à idade limite, foi-lhe prestada carinhosa homenagem, na abertura dos cursos, em 31 de março de 1938. Falou pela Congregação o professor Vicente Ráo, que dedicou ao saudoso mestre a primeira parte da lição inaugural que então proferiu.

Agradecendo, proferiu o homenageado palavras comovidas, nas quais se patenteiam a sua modéstia e o seu gran- 
de amor a esta Casa. Do seu formoso discurso, destaco estas passagens: "Ensinei ciência, na diminuta medida das minhas fôrças, aos meus alunos, no propósito de oferecerIhes um jardim; e êles, em compensação, me ensinaram também como embelezá-lo, ofertando flores. Assim irmanados, caminhamos unidos para um ideal de beleza, já sintetizado por alguem, que havia dito: "A ciência é um jardim, a literatura é a flor; sem a flor, que beleza terá o jardim?" "E concluia: "E neste instante em que desaparece a plenitude do meu magistério, só me restará aguardar a hora fatal em que a "lágrima" significativa há de surgir para, derramada, se evolar nas azas brancas de uma saudade viva, e, então, buscar olhar, por derradeiro momento, êste ninho do pensamento e do estudo, êste castelo de honestidade intelectual, esta menina dos meus olhos; e, de pé, se possível, bradar, parodiando os soldados de Cesar: "Ave! Faculdade de Direito! Moriturus, te saluto!"

Não há quem passe pela Faculdade sem amá-la, sem a ela ficar preso pelo resto da vida.

Quem nela entra, vendo-lhe as arcadas, tem a impressão de haver penetrado em um templo que ainda permanece como no passado, graças à veneração dos homens. Não lhe faltam os numes tutelares dos Romanos, representados pelos nomes que fizeram a Academia grande e augusta.

É um templo do Direito e também da Pátria, sendo as palavras o incenso e a mirra do culto que aquí praticamos - professores e alunos, todos, ao mesmo tempo, sacerdotes e fieìs dêsse culto.

"A alma vive no que ama", diz Valério Máximo. Sousa Carvalho, que tanto amou esta Faculdade, aquí viveu. E nela continuará a viver a sua lembrança.

Quís êle, ao morrer, saudar a querida Academia. Esta também o saudará perenemente, guardando, com carinho, 2. sua memória. 